\title{
Laser Heating and Infrared Thermography of Building Materials
}

\author{
Aschalew Kassu ${ }^{*}$, Carlton Farley III $^{2}$, Christina P. Tsoli ${ }^{3}$ \\ ${ }^{1}$ Department of Mechanical, Civil Engineering and Construction Management, Alabama A \& M University, Huntsville, AL, USA \\ ${ }^{2}$ Department of Physics, Chemistry, and Mathematics, Alabama A \& M University, Huntsville, AL, USA \\ ${ }^{3}$ Department of Chemistry, National and Kapodistrian University, Athens, Greece \\ Email: *aschalew.kassu@aamu.edu
}

How to cite this paper: Kassu, A., Farley III, C. and Tsoli, C.P. (2021) Laser Heating and Infrared Thermography of Building Materials. Journal of Building Construction and Planning Research, 9, 223-229. https://doi.org/10.4236/jbcpr.2021.93014

Received: June 14, 2021

Accepted: August 10, 2021

Published: August 13, 2021

Copyright () 2021 by author(s) and Scientific Research Publishing Inc. This work is licensed under the Creative Commons Attribution International License (CC BY 4.0).

http://creativecommons.org/licenses/by/4.0/

\begin{abstract}
In this work, a $532 \mathrm{~nm}$ diode CW laser is used to heat samples used as building materials at a 1 meter standoff distance while using an FLIR (Forward-Looking Infrared) thermal camera to monitor and record the heating and then cooling of each sample after lasers are switched off. The data is then analyzed using FLIR proprietary software. Since the absorption spectra of materials are unique, using multiple lasers of different wavelengths to simultaneously shine onto the sample at different locations would give enough thermal data to successfully characterize the samples within a reasonable amount of time. The results are very promising for applications involving non-destructive detection and classification of materials.
\end{abstract}

\section{Keywords}

Infrared Thermography, NIR, Thermal, Laser Heating, Remote Detection

\section{Introduction}

In the construction industry, infrared thermography (IRT) is one of the valuable techniques for estimating the thermal transmittance (U-value) of buildings and evaluation of energy efficiency of existing buildings [1]-[6], thermal performances of insulating glasses (glazing) [7], identification of cracks and defects [8] [9], air leakage [10], the density of construction materials [11], and quality control of building materials [6]. The application of IRT for IR thermal rehabilitation survey of existing buildings and improving thermal resistance and thermal comfort of the building envelope has also been demonstrated. Measurement of the $U$-value of existing buildings enables quantitative measurement and evaluation of the building envelopes' energy efficiency and performance [1] [2] [3]. 
However, the effect of varying climatic factors on IRT images significantly affects the U-values of the buildings [12].

The IR radiation acquired from the remotely located target surface representing the surface's temperature distribution converted into electrical signals and processed to produce IR images, revealing valuable information about the surface-emitting radiation [13] [14]. The non-destructive nature of IRT technique for inspection, testing, and evaluation of materials and assessment of defects also makes it an attractive sensor in studying murals, historical monuments, and preserves the structures and implements preventive diagnostics [9] [15] [16] [17] [18] [19]. D. Gonzalez-Aguilera [3] demonstrated a 3D-IR image-based thermographic modeling approach to evaluate the energy efficiency of the building envelope. The study used building facades composed of brick and concrete and double glass aluminum frame windows.

Analysis of thermal patterns of IRT images acquired from the building envelope provides information on the cracks' location and identifies defects and decays in building materials due to humidity. By superimposing the IR images of buildings captured before the earthquake (2003-2008) with the IR-images after the 2009 earthquake in Italy, Fabio Bisegna [9] studied the impacts of the earthquake on buildings. The study evaluated the buildings' thermal patterns, and the results of the IRT diagnostics study were used for identifying the locations of cracks for the rehabilitation of the structures. During the construction stages of buildings, IRT is used for quality control of the materials to be used for testing the thermal performances of building materials during various phases of the construction process [6]. The remote infrared thermographic inspection of the surface temperature and the IR images captured have also been used to determine the density of materials, including different species of timber structures used in buildings [11].

This section summarized the literature on the applications of infrared thermography for identifying crack locations in buildings, assessing defects on the structures, estimating the U-value of the building envelope, and the density of the construction materials used. The present work reports a proof of concept on measuring the heating and cooling rates of several different types of building materials exposed to a $100 \mathrm{~mW}, 532 \mathrm{~nm}$ diode laser and captured by an FLIR T-50 thermal camera at a 1-meter stand-off distance. Materials and methods are discussed in the next section, while results are shown afterwards.

\section{Materials and Methods}

Several samples were purchased from a local hardware store, while some materials from our lab were used for preliminary measurements. The samples used in the study include brick, concrete block, cedar wood and poplar wood, roofing shingle, PVC pipe, ceramic tile, and plastics.

A FLIR T-540 thermal camera was used to record thermal video from a stand-off distance of $1 \mathrm{~m}$ while a $100 \mathrm{~mW} 532 \mathrm{~nm}$ diode laser is shone onto each sample for about 10 seconds. The temperature of the spot the laser hits the sam- 
ple will begin to increase while the laser is switched on, then will decrease when the laser is switched off. FLIR Tools software is used to process the images, while Microsoft Excel is used to process the data. Data curves during heating and during cooling appear to be unique for each material. Data curves are baseline-subtracted, and line integrals are calculated to show differences between each material. The $532 \mathrm{~nm}$ diode laser and FLIR T-540 thermal camera are both battery-powered and lightweight, making this a portable setup that can be used both indoors as well as outdoors.

\section{Results and Discussions}

Ten different samples including concrete block, brick, poplar wood, cedar wood, roofing shingle, ceramic tile (white), PVC pipe (white), plumbing coupling (black), plastic (dark), and slate were used for laser heating studies. Figure 1 shows concrete block and roofing shingles with a laser beam being shined onto the concrete block and roofing shingle samples individually. A $532 \mathrm{~nm}, 100$ $\mathrm{mW}$ diode laser was shined onto each sample for about $10 \mathrm{~s}$ while thermal measurements were taken using an FLIR T-540 camera in video capture mode. The samples were allowed to cool down to their original temperature after being heating.

Figure 2 and Figure 3 show temperature versus time graphs at a single position, denoted by crossbars for each sample. The temperature rises as the laser light are being shined onto the sample, and then the sample cools down after the laser is switched off. The rates of heating and cooling may provide insight into the type of material being used. Simple data analysis techniques could be used to distinguish and identify different types of materials.
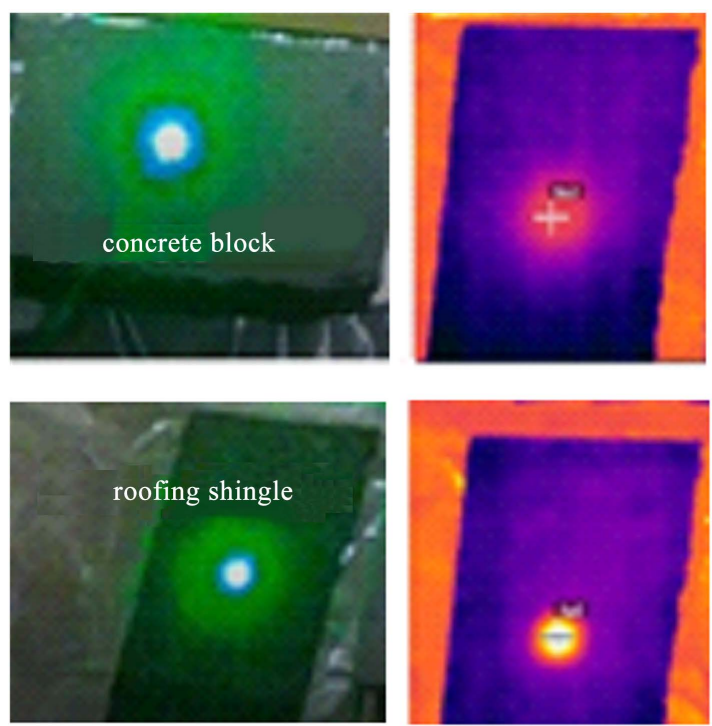

Figure 1. Images of concrete block and roofing shingles. The left images show $532 \mathrm{~nm}$ laser being shined onto the concrete block and roofing shingle samples individually, while right thermal images show localized heating of the samples. The crossbars on the thermal images show locations for temperature measurements. 


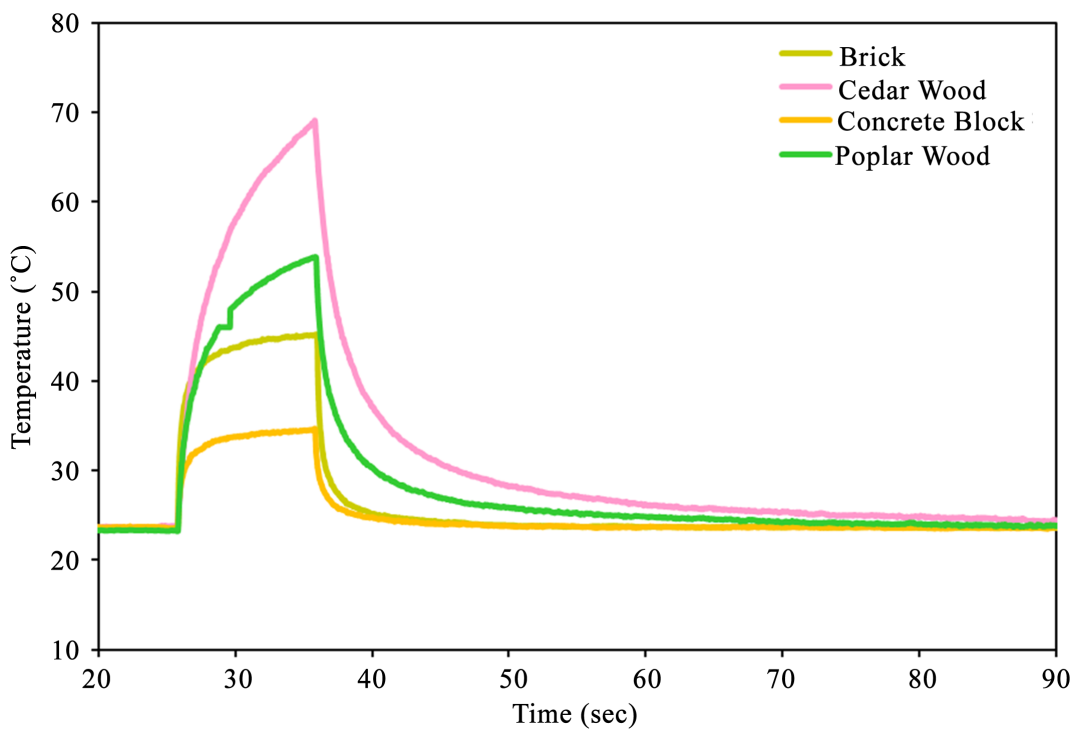

Figure 2. Temperature change due to laser heating of brick, concrete block, cedar wood and poplar wood samples. $532 \mathrm{~nm}$ laser was switched on at about $25 \mathrm{~s}$, then switched off at about $35 \mathrm{~s}$, then the sample was allowed to cool.

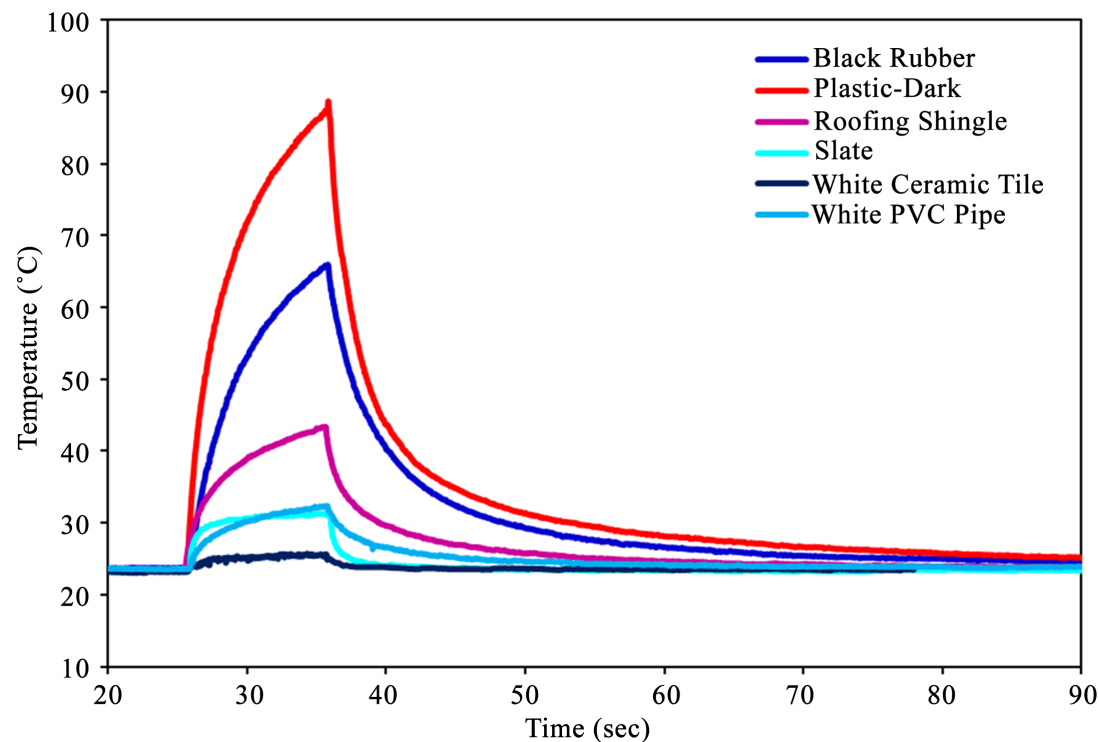

Figure 3. Temperature change due to laser heating of roofing shingle, PVC pipe, ceramic tile, and plastics samples. $532 \mathrm{~nm}$ laser was switched on at about $25 \mathrm{~s}$, then switched off at about $35 \mathrm{~s}$, then the sample was allowed to cool.

All the samples are seen to have different rates of heating and cooling, which indicates the possible usefulness of this method for identifying and distinguishing different targets/materials in the field. For the same laser power and exposure time, the peak temperatures recorded for concrete, brick, poplar wood and cedar wood were about $35^{\circ} \mathrm{C}, 45^{\circ} \mathrm{C}, 54^{\circ} \mathrm{C}$ and $69^{\circ} \mathrm{C}$ respectively (Figure 2). As can be seen in Figure 3, the peak temperatures recorded using FLIR T-540 camera for white ceramic tile, white PVC pipe and roofing shingle were $25^{\circ} \mathrm{C}, 32^{\circ} \mathrm{C}$ and $43^{\circ} \mathrm{C}$. The results in Figure 2 and Figure 3 show that the rubber and plastic 
Table 1. Thermal conductivity and line integrals during heating and cooling.

\begin{tabular}{cccc}
\hline Material & Thermal Conductivity & Heating & Cooling \\
\hline Dark plastic (polypropylene) & $0.1-0.22$ & $11,593.9$ & 9786.4 \\
Cedar wood & $0.12-0.19$ & 8768.9 & 7631.9 \\
Poplar wood & $0.12-0.19$ & 5956.2 & 3509.8 \\
Black PVC rubber) & 0.19 & 8290.9 & 8813.5 \\
White PVC pipe & 0.19 & 1849.3 & 1204.1 \\
Brick & $0.6-1.0$ & 3563.0 & 1079.5 \\
Roofing shingle (asphalt/ceramic) & $0.75 / 3.0-5.0)$ & 3164.9 & 2933.8 \\
Concrete block & $0.4-1.8$ & 1869.9 & 724.9 \\
Black slate tile & 2.01 & 1871.3 & 678.8 \\
White ceramic tile & $3.0-5.0$ & 437.5 & 309.3 \\
\hline
\end{tabular}

samples heat up rapidly followed by cedar wood and poplar wood. Though the laser was allowed to shine onto each sample for about 10 seconds, a laser of a higher power may be used to achieve similar results in a much shorter time. The absorption spectrum for each material is different, so it will be useful to heat samples with several different lasers and monitor results. This may be done simultaneously at different spots on each sample as the FLIR T-540 can take video data. These measurements can be taken both indoor and outdoor during daylight hours using a $532 \mathrm{~nm} 100 \mathrm{~mW}$ laser to heat the samples at stand-off distances, while the FLIR T-540 thermal camera is used to capture the thermal images and the corresponding changes in temperature.

Table 1 shows the thermal conductivity of each material [20], plus baseline-subtracted line integrals during the heating and cooling processes of the materials studied (Figures 1-3). Generally, as the thermal conductivity increases, the value of both line integrals will decrease. Exceptions are seen in the table but are easily accounted for by the color of the material. Colors that are darker tend to absorb a higher percentage of the $532 \mathrm{~nm}$ laser light than colors that are lighter, due to reflection.

\section{Conclusion}

The results of the $532 \mathrm{~nm}, 100 \mathrm{~mW}$ continuous wave laser heating at a stand-off distance of 1 meter, and infrared thermography of building materials including concrete block, bricks, roofing shingle, PVC pipes, cedar wood and poplar wood samples using FLIR T-540 IR-thermal camera have been presented. The exposure time used to heat the samples was about 10 seconds, and periodically the laser was switched on and off while the IR images were collected using IR camera. The results presented indicate that different materials possess unique properties and respond differently while heated using a laser beam and the IR thermographic images collected, and the spectral absorption signatures are characteristics of the building materials studied. Future work in this area should include 
the use of multiple lasers of different wavelengths to be shone onto different spots of each sample. Also, several different colors of each material should be used. This would allow for the creation of a database of many materials of various colors, where more sophisticated types of data analysis could be completed quickly for rapid identification of materials. It would also be interesting to take measurements at distances larger than 1 meter, which may lead to specialized applications of this technique.

\section{Conflicts of Interest}

The authors declare no conflicts of interest regarding the publication of this paper.

\section{References}

[1] Albatici, R., Tonelli, A.M. and Chiogna, M. (2015) A Comprehensive Experimental Approach for the Validation of Quantitative Infrared Thermography in the Evaluation of Building Thermal Transmittance. Applied Energy, 141, 218-228. https://doi.org/10.1016/j.apenergy.2014.12.035

[2] Fokaides, P.A. and Kalogirou, S.A. (2011) Application of Infrared Thermography for the Determination of the Overall Heat Transfer Coefficient (U-Value) in Building Envelopes. Applied Energy, 88, 4358-4365. https://doi.org/10.1016/j.apenergy.2011.05.014

[3] González-Aguilera, D., Lagüelab, S., Rodríguez-Gonzálveza, P. and Hernández-López, D. (2013) Image-Based Thermographic Modeling for Assessing Energy Efficiency of Buildings Facades. Energy and Buildings, 65, 29-36. https://doi.org/10.1016/j.enbuild.2013.05.040

[4] Nardi, I., Paoletti, D., Ambrosini, D., de Rubeis, T. and Sfarra, S. (2016) U-Value Assessment by Infrared Thermography: A Comparison of Different Calculation Methods in a Guarded Hot Box. Energy and Buildings, 122, 211-221. https://doi.org/10.1016/j.enbuild.2016.04.017

[5] Ficco, G., Iannetta, F., Ianniello, E., Alfano, F.R.D. and Dell'Isola, M. (2015) U-Value in Situ Measurement for Energy Diagnosis of Existing Buildings. Energy and Buildings, 104, 108-121. https://doi.org/10.1016/j.enbuild.2015.06.071

[6] Taylor, T., Counsell, J. and Gill, S. (2013) Energy Efficiency Is More than Skin Deep: Improving Construction Quality Control in New-Build Housing Using Thermography. Energy and Buildings, 66, 222-231. https://doi.org/10.1016/j.enbuild.2013.07.051

[7] Maroy, K., Carbonez, K., Steeman, M. and Van Den Bossche, N. (2017) Assessing the Thermal Performance of Insulating Glass Units Withinfrared Thermography: Potential and Limitations. Energy and Buildings, 138, 175-192.

https://doi.org/10.1016/j.enbuild.2016.10.054

[8] Tran, Q.H., Han, D., Kang, C., Haldar, A. and Huh, J. (2017) Effects of Ambient Temperature and Relative Humidity on Subsurface Defect Detection in Concrete Structures by Active Thermal Imaging. Sensors, 17, 1718.

https://doi.org/10.3390/s17081718

[9] Bisegna, F., Ambrosini, D., Paoletti, D., Sfarra, S. and Gugliermetti, F. (2014) A Qualitative Method for Combining Thermal Imprints to Emerging Weak Points of Ancient Wall Structures by Passive Infrared Thermography-A Case Study. Journal 
of Cultural Heritage, 15, 199-202. https://doi.org/10.1016/j.culher.2013.03.006

[10] Barreira, E., Almeida, R.M.S.F. and Moreira, M. (2017) An Infrared Thermography Passive Approach to Assess the Effect of Leakage Points in Buildings. Energy and Buildings, 140, 224-235. https://doi.org/10.1016/j.enbuild.2017.02.009

[11] López, G., Basterra, L.A. and Acuña, L. (2013) Estimation of Wood Density Using Infrared Thermography. Construction and Building Materials, 42, 29-32. https://doi.org/10.1016/j.conbuildmat.2013.01.001

[12] Lehmann, B., Wakili, K.G., Frank, Th., Collado, B.V. and Tanner, Ch. (2013) Effects of Individual Climatic Parameters on the Infrared Thermography of Buildings. Applied Energy, 110, 29-43. https://doi.org/10.1016/j.apenergy.2013.03.066

[13] Barreira, E. and de Freitas, V.P. (2007) Evaluation of Building Materials Using Infrared Thermography. Construction and Building Materials, 21, 218-224. https://doi.org/10.1016/j.conbuildmat.2005.06.049

[14] Usamentiaga, R., Venegas, P., Guerediaga, J., Vega, L., Molleda, J. and Bulnes, F.G. (2014) Infrared Thermography for Temperature Measurement and Non-Destructive Testing. Sensors, 14, 12305-12348. https://doi.org/10.3390/s140712305

[15] Avdelidis, N.P. and Moropoulou, A. (2004) Applications of Infrared Thermography for the Investigation of Historic Structures. Journal of Cultural Heritage, 5, 119-127. https://doi.org/10.1016/j.culher.2003.07.002

[16] Kordatos, E.Z., Exarchos, D.A., Stavrakos, C., Moropoulou, A. and Matikas, T.E. (2013) Infrared Thermographic Inspection of Murals and Characterization of Degradation in Historic Monuments. Construction and Building Materials, 48, 1261-1265. https://doi.org/10.1016/j.conbuildmat.2012.06.062

[17] Paoletti, D., Ambrosini, D., Sfarra, S. and Bisegna, F. (2013) Preventive Thermographic Diagnosis of Historical Buildings for Consolidation. Journal of Cultural Heritage, 14, 116-121. https://doi.org/10.1016/j.culher.2012.05.005

[18] Marrocchino, E., Telloli, C., Aprile, A., Capuani, D., Malaguti, D. and Vaccaro, C. (2021) Case Study on the Mineralogical and Petrophysical Analysis of Reinforced Concrete Slabs of a Highway Viaduct of the S.G.C. Orte-Ravenna. SN Applied Sciences, 3, 623. https://doi.org/10.1007/s42452-021-04620-6

[19] Garrido, I., Lagűela, S., Otero, R. and Arias, P. (2020) Thermographic Methodologies Used in Infrastructure Inspection: A Review Post-Processing Procedures. Applied Energy, 266, Article ID: 114857. https://doi.org/10.1016/j.apenergy.2020.114857

[20] https://www.engineeringtoolbox.com/thermal-conductivity-d 429.html 